\title{
Concepções estereotipadas sobre o aquecimento global em livros didáticos de química
}

\section{Evelyn Jeniffer de Lima Toledo} Jeniffer.toledo@gmail.com 0000-0003-4266-4377 sília, Distrito Federal, Brasil.

Luiz Henrique Ferreira ferreiraufscar@gmail.com

Universidade Federal de São Carlos, São Paulo, Brasil.

\section{RESUMO}

O período atual é marcado por um amplo acesso a informações, porém o conteúdo destas é questionável tendo em vista a superficialidade e o exagero emocional que as caracterizam. Este artigo visa avaliar como o efeito estufa é discutido nos livros didáticos de Química aprovados no PNLEM 2008 e PNLD 2012 questionando se fortalecem uma visão estereotipada do fenômeno. Os resultados sugerem que o tom catastrófico está presente tanto na forma textual quanto imagética colaborando para que seja tênue a linha entre a notícia estereotipada proposital e aquela advinda do desconhecimento. Essa abordagem realizada pelos livros didáticos caminha na contramão da LDB e PCNs, pois ao omitir o caráter controverso apresentando uma visão única, usurpa do aluno a oportunidade de desenvolver sua criticidade, o que poderia ser favorecido através dos princípios básicos da filosofia científica fundamentando o significado de ciência ao enfatizar a impossibilidade de chegar a uma verdade absoluta.

PALAVRAS-CHAVE: Efeito estufa. Livro didático. Pensamento crítico. 


\section{INTRODUÇÃO}

Os processos de ensino e aprendizagem do conhecimento científico não são triviais, isso porque o conjunto de modelos e teorias a eles pertencentes é em sua maioria abstrato. Essa abstração exige dos estudantes e do professor mediador altas habilidades cognitivas sendo condition sine qua non considerar todas as visões deformistas que a literatura relata.

Pérez et al. (2001) relata sete deformações, para as quais é preciso muita atenção para não se vitimar passiva ou ativamente, são elas:

- (1) Concepção empírico-indutivista e ateórica: considera que as observações acontecem em um vazio conceitual relevando as hipóteses e todas as concepções prévias do observador que construiria a ciência de forma neutra.

- (2) Visão rígida: considera a ciência como uma sequência de passos organizados adequados a estruturação de qualquer modelo ou teoria, pois todos estão sujeitos ao Método Científico.

- (3) Visão aproblemática e ahistórica: o conjunto de teorias e modelos parece ter origem no acaso, pois não são resultados do questionamento de cientistas e tampouco estão correlacionados com um período do tempo e seu contexto.

- (4) Visão analítica: responsável pela fragmentação da ciência na tentativa de melhor compreende-la, mas sem considerar a necessária unificação dos fragmentos na busca por respostas mais amplas.

- (5) Visão acumulativa de crescimento linear: o desenvolvimento da ciência se dá de forma sequencial sem sofrer rupturas e revoluções, vai sendo acumulado no decorrer do tempo.

- (6) visão individualista e elitista da ciência: vende-se a ideia de que o conhecimento científico é construído por gênios isolados, prioritariamente do sexo masculino, e que o trabalho coletivo, o intercâmbio de resultados em nada tem contribuído para a validação ou refutação de hipóteses.

- (7) visão descontextualizada e socialmente neutra: Abnegam as relações entre ciência, tecnologia e sociedade colocando o cientista alheio às questões do mundo.

Os problemas relacionados às visões deformadas da natureza da ciência vão desde um distanciamento do aprendiz com o cientista, fomentando a possibilidade do primeiro não ser capaz de se ver na posição do segundo e, portanto construir a crença de que jamais poderá ser um cientista, até a dificuldade em se compreender os modelos e teorias, pois tamanha abstração ancorada ao nada devido à ausência de contextualização e problematização dificilmente conduzirá a uma aprendizagem significativa. Além disso, é passível à construção de uma percepção equivocada de que uma teoria científica é uma verdade absoluta transfigurada em uma representação da realidade a espera de um gênio que a descubra.

Dessa forma, é preciso que fique claro que a ciência não é a representação da realidade, ela permite a construção de modelos provisórios capazes de explicarem alguns fenômenos em situações especificas. Portanto, uma teoria será boa enquanto explica o original de forma precisa. É natural imaginar que se os 
resultados são bons a teoria corresponde à verdade. Entretanto ela sempre estará sujeita a não funcionar completamente, podendo então ser substituída por outra mais eficaz. Nesse momento ocorrem as grandes revoluções na ciência (ALVES, 1981).

A ciência progride por tentativa e erro, hipóteses e refutações. Apenas as teorias mais adaptadas sobrevivem, embora nunca se possa dizer que uma teoria é verdadeira, pode-se dizer que é a melhor disponível (CHALMERS, 1993). Segundo Kuhn (1998) a ciência pode ser resumida da seguinte forma: Pré-ciência -> Ciência normal -> Crise-> Revolução -> Nova ciência normal -> Nova crise (Figura 1).

Figura 1- A estrutura da construção cientifica

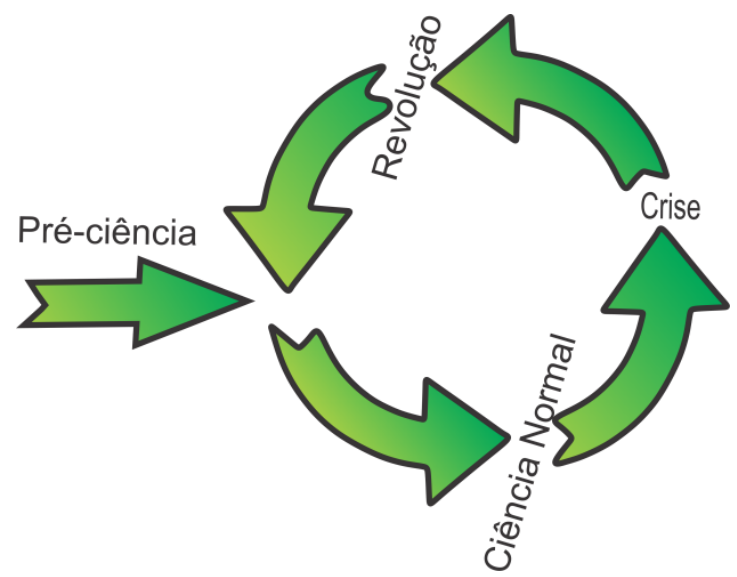

(Fonte: imagem autoral)

Pré-ciência: é o estado que a atividade científica encontra-se desorganizada. Há um total desacordo e um constante debate sobre os fundamentos, o que torna impossível se dedicar ao trabalho esotérico.

Ciência normal: a atividade científica encontra-se estruturada pela adoção de um paradigma. Os cientistas desenvolverão o paradigma, teórica e experimentalmente, na tentativa de explicar e prever o comportamento de alguns aspectos do mundo real de forma confiante. Entretanto, pode-se deparar com dificuldades, como enigmas que não podem ser resolvidos, anomalias que não podem ser explicadas, e aparentes falsificações da teoria, o que não necessariamente corresponde a uma crise. No entanto, esses fracassos da teoria podem atingir um grau de seriedade que constitui uma crise. Um fracasso é considerado sério se atacar os próprios fundamentos de um paradigma de forma que os membros da comunidade científica normal não consigam resolvê-lo.

Crise: no período de crise as tentativas de resolver os problemas se tornam cada vez mais radicais e as regras vão se tornando mais frouxas para sustentar o sistema (teoria-observação), estado que piora quando aparece um paradigma rival. É interessante notar como alguns cientistas começam a expressar abertamente sua insatisfação: 
Revolução: uma crise é resolvida quando surge um paradigma novo que atrai a adesão de um número crescente de cientistas. Para que a revolução seja bemsucedida, este deslocamento deverá ocorrer de modo a incluir a maioria da comunidade científica, sobrando apenas alguns que serão excluídos e que em algum momento morrerão. Neste momento, os cientistas, como Wolfgan Pauli, expressam sua satisfação e alivio:

O tipo de Mecânica proposta por Heisenberg devolveu-me a esperança e a alegria de viver. Sem dúvida alguma, ela não proporciona a solução para a charada, mas acredito que agora é possível avançar novamente (KUHN, 1998, p.115).

Nova ciência normal: o novo paradigma resulta em uma nova atividade científica normal até que novos e sérios problemas apareçam resultando em uma nova crise e posteriormente em uma nova revolução.

Não se deve esperar que um paradigma seja perfeito, todos serão inadequados em algum ponto no que se refere a sua correspondência com a natureza. Essa é a função das revoluções, essenciais para o progresso da ciência (CHALMERS, 1993).

Assim, a comunidade científica oscila em épocas de consenso e épocas de discórdia, pois apesar das teorias serem temporais elas não mudam ao longo do tempo de forma desorientada, já que são quase sempre fruto de dezenas de anos em busca de afirmação e não um simples processo de substituição e de revisão. As novas teorias são, quase sempre, recebidas com muito ceticismo, poucas sobrevivem às rigorosas provas. Não se trata de um processo de acumulação, mas de mudança, incluindo mudanças na forma de pensar (PRAIA; CACHAPUZ; GIL-PEREZ, 2002).

Quando uma teoria é enunciada ela tenta representar um sistema e prever como ele deverá se comportar no futuro. Assim, para testá-la deve-se verificar se o comportamento no futuro equivale ao que foi previsto (ALVES, 1981), as verificações relevantes são aquelas que a colocam em risco e tentam falseá-la. Uma vez que seja submetida à prova e comprove sua qualidade, ela se torna mais forte (POPPER, 1972), o número de testes pelo qual passou não garante sua veracidade e assim, sempre estará sujeita a refutação. Quando um cientista se depara com um experimento que contradiz a teoria ele não a abandona de imediato, pois isso implicaria em negar grande parte de sua trajetória acadêmica, chocar-se com os pares e assim sujeitar-se a arriscar sua fonte de financiamento. Rejeitando as contra-evidências, ele tenta manter suas convicções permanecendo em sua zona de conforto intelectual (RUFATTO, 2009), muitas vezes omite os dados conflitantes, embora estes sejam a parte mais importante e significativa da pesquisa por poder dar origem a novos paradigmas (ALVES, 1981).

A tentativa em permanecer na sua zona de conforto intelectual e a postura dogmática frente à ciência é também incorporada por uma parcela da sociedade que, sendo leiga, compra os equívocos divulgados pela grande mídia. Revistas, televisões e jornais constantemente fazem propagandas que vinculam a qualidade de um produto com o clichê "cientificamente comprovado" induzindo 
o espectador a crer que a palavra do cientista tem a força de uma verdade incontestável. Além de alguns cientistas e da Mídia, é possível observar esse comportamento em alguns professores que ao fazerem uso de experimentos na sala de aula objetivam comprovar teorias. Assim, os modelos ganham um caráter de verdade absoluta como se substituíssem a crença em um Deus pela crença na Ciência. Então, a ciência é estereotipada como detentora de todo o saber e suas teorias são assumidas como representações da realidade. Não há nada no universo cientificamente comprovado, acreditar no contrário é assumir que os cientistas ficaram frente a frente com o original para que a partir deste pudesse elaborar sua réplica. Entretanto, o que se tem na ciência não são cópias da realidade, mas representações que funcionam adequadamente em algumas situações (ALVES, 1981).

Todos os que têm certezas estão condenados ao dogmatismo. Se estou certo da verdade de minha teoria, por que motivos haveria de perder tempo ouvindo uma outra pessoa que, por ter ideias diferentes, tem de estar errada? As certezas andam sempre de mãos dadas com as fogueiras...(ALVES, 1981, p.150).

Entre as diversas discussões científicas, o meio ambiente tem sido alvo de atenção desde a publicação do livro Primavera Silenciosa em 1962, através do qual a autora Rachel Carson, preocupada com o planeta Terra, coaptou ativistas e cientistas na luta pelo banimento de pesticidas.

A preocupação com o futuro do planeta e a vida na Terra não se limita ao uso de pesticidas, mas é permeada por diversas teorias, dentre elas a do Efeito Estufa, assunto recorrente tanto na literatura acadêmica quanto na mídia comum, embora muitas vezes por um viés estereotipado.

A teoria do Efeito Estufa foi elaborada na tentativa de explicar a diferença entre a temperatura teórica e experimental da Terra, pois ao considerar a projeção bidimensional da radiação emitida pelo Sol e o albedo planetário, segundo Arrhenius (1986), a temperatura média da Terra deveria ser $-15{ }^{\circ} \mathrm{C}$, porém a temperatura mensurada era de $15{ }^{\circ} \mathrm{C}$, ou seja, 30 graus acima do previsto. Diante dessas informações, os cientistas tinham duas opções: 1) Rever essas afirmações e assim descontruir as teorias envolvidas nos cálculos ou; 2) Agregar novas informações que explicassem a diferença de temperatura observada. A opção adotada por Arrhenius (1896) foi acrescentar novas variáveis ao sistema através da influência da composição da atmosfera na temperatura, o que resultou na elaboração da Teoria do Efeito Estufa.

Segundo a Teoria do Efeito Estufa, parte da radiação ultravioleta (UV) e/ou ultravioleta-visível (UV-vis) emitida pelo Sol que chega a superfície da Terra é absorvida e então emitida na forma de infravermelho (I.V.). Porém, como o caminho no espaço é longo e preenchido por vários tipos de átomos e moléculas, a radiação pode encontrar alguma substância capaz de absorvê-la dificultando sua trajetória. Assim, as velocidades de entrada e saída da radiação na atmosfera terrestre não são equivalentes, mas situam-se em um aparente equilíbrio mantendo a temperatura média estável. A partir desta teoria foi inferido que como o equilíbrio da temperatura era resultado da concentração de gases capazes de absorverem a radiação infravermelha, essa temperatura poderia ser modificada a partir da variação dessa concentração gerando um esfriamento ou um aquecimento global se ela diminuísse ou aumentasse, respectivamente. Uma 
segunda teoria foi deduzida a partir dessa, nela os cientistas alegam estar havendo um aumento da concentração dos gases estufa por ação antrópica e, portanto, culpabiliza o homem pelo aquecimento global.

Deste modo, a temperatura média da Terra não é resultado do Efeito Estufa, mas é o Efeito Estufa a melhor explicação, hoje, para a temperatura mensurada. Essa inversão da lógica causa/efeito transmite a ideia de que o Efeito Estufa é uma verdade descoberta, uma expressão da realidade - uma verdade absoluta!

As consequências previstas pelos adeptos do aquecimento global são várias, dentre elas destacam-se (CLIMATE, 2014):

-Derretimento das geleiras e consequentes redistribuições geográficas de espécies terrestres, aquáticas e marinhas, com algumas extinções, além do aumento do nível do mar;

-Maior mortalidade ocasionada pelo calor;

-Insegurança alimentar ocasionado pelas secas e inundações, principalmente para a população mais pobre;

-Perda de biodiversidade;

-Redução da qualidade da água;

- Inundações, submersão e erosão em sistemas costeiros;

-Risco de doenças transmitidas pela água e por vetores.

Embora de forma geral a maior atenção seja atribuída às possibilidades negativas de um aquecimento global e/ou aumento da concentração do dióxido de carbono, é necessário considerar que há também fatos favoráveis como o aumento da produtividade de algumas culturas como a do feijão e a de árvores de crescimento rápido (MOSCATI, 2007), diminuição da mortalidade pelo frio (CLIMATE, 2014). Além disso, estudos evidenciam que plantas desenvolvidas em uma atmosfera rica em $\mathrm{CO}_{2}$ são mais resistentes a variações bruscas de temperatura, formam raízes mais fortes e precisam de menos água (BLUCHEL, 2008). Ademais, estudos associam o aumento do $\mathrm{CO}_{2}$ e da temperatura com o desenvolvimento das florestas tropicais: um aumento de $2^{\circ} \mathrm{C}$ faria a Terra retornar às condições climáticas de aproximadamente 5000 a 6000 anos atrás, período no qual se desenvolveram exuberantes florestas tropicais no planeta (SILVA; FERNANDES, 2010).

Embora a grande maioria dos cientistas concorde que estamos vivenciando um período de aquecimento global e que este está sendo agravado pelo homem, essa posição não é unânime. Em 1929 Simpson já afirmava que as variações na concentração de $\mathrm{CO}_{2}$ atmosférico não seriam capazes de causar variações significativas no clima, pois a banda de absorção do $\mathrm{CO}_{2}$ não é apenas estreita como sobreposta pela banda de vapor de água que, portanto teria muito mais influência (ONÇA, 2015).

Além disso, entre as décadas de 1960 e 1970, passa a crescer uma discussão afirmando que a Terra estaria vivenciando um período de resfriamento, já que a temperatura naquele período estava diminuindo (ONÇA, 2015).

Para refutar a teoria do aquecimento global antropogênico pesquisadores indicam vários aspectos: 
1) $\mathrm{O} \mathrm{CO}_{2}$ não deve ser considerado o principal gás estufa, esta posição foi atribuída ao vapor de água. Além disso, a concentração de $\mathrm{CO}_{2}$ já foi tão alta quanto a atual e o problema estaria na metodologia de análise de bolhas de ar aprisionadas no gelo, pois ao considerar que as bolhas não sofrem alterações mesmo após milhares de anos, subestimam os resultados em 30 a 50\%. Isso porque a composição da bolha de ar não permanece inalterada por tanto tempo devido à ocorrência de reações químicas e também por causa da difusão de ar ocasionada pelas altas pressões (chegam a ser mais de 300 vezes superiores às da atmosfera). Além disso, a diferença de idade entre a bolha de ar e o gelo que a aprisionou torna a comparação entre concentrações inadequadas (MOLION, 2008).

2) O aumento da concentração de $\mathrm{CO}_{2}$ nos séculos passados ocorreu devido à um aquecimento natural da Terra, uma temperatura maior nos oceanos diminuiu a solubilidade do $\mathrm{CO}_{2}$ liberando-o para a atmosfera. Assim, não seria o aumento da concentração de $\mathrm{CO}_{2}$ que causou o aumento da temperatura, mas o aumento da temperatura que estaria ocasionando o aumento da concentração de $\mathrm{CO}_{2}$ (MOLION, 2008).

3) O aumento detectado de aproximadamente $0,7^{\circ} \mathrm{C}$ (principal evidência da corrente antropogênica) é irrisório e situa-se muito próximo as incertezas entre as medidas realizadas no passado com as atuais, que são elevadas quando se considera a não padronização das estações climatométricas, tanto tecnologicamente quando em termos de localização geográfica (MOLION, 2007). Afinal, não se pode ignorar que as ilhas de calor ocasionadas pela grande quantidade de construções e de poluentes causa um aumento da irradiação de calor na atmosfera localmente (BARROS; SOUSA; SOUZA, 2014). Somado a isso, o início das séries utilizadas pelos pesquisadores da corrente antrópica ocorreu num período relativamente mais frio que o atual levando à conclusão errônea de que as temperaturas atuais sejam muito altas para o planeta (MOLION, 2007).

4) Os modelos computacionais indicam que a temperatura média da Terra já deveria ter se elevado a uma faixa entre 0,5 e $2,0^{\circ} \mathrm{C}$, porém o aumento mensurado situa-se entre 0,4 e $0,7^{\circ} \mathrm{C}$, ou seja, aquém da expectativa, evidenciando a inadequabilidade dos modelos (MOLION, 2008).

Para os adeptos da teoria da ação natural, as consequências apontadas pelos seguidores das correntes antrópicas não passam de processos geológicos naturais: continentes colidem e separam, vulcões entram em erupção, terremotos acontecem, espécies extinguem-se e outras surgem, geleiras expandem e retraem, o clima muda, o nível dos mares varia como sempre ocorreu porque a natureza está em constante transformação e não existe equilíbrio (MOLION, 2007), há mais de 4 bilhões de anos a Terra vivencia períodos quentes seguidos por Eras do gelo (MOZETO, 2001).

A corrente que defende variações de temperatura como um efeito natural não apenas nega o efeito antrópico como afirma que os próximos anos serão de um arrefecimento global ao invés do defendido aquecimento (MOLION, 2007).

Portanto, ambos os grupos apresentam um conjunto de argumentos e evidências relevantes. Entretanto, o clima é muito complexo, envolve controles internos e externos ao sistema terra-atmosfera-oceano, dos quais o efeito-estufa é apenas um dos processos. Existem outros fatores a serem levados em consideração como Atividade Solar, Campo Magnético, Eixo de inclinação da 
Terra, Radiação Cósmica, Erupções Vulcânicas (SILVA; FERNANDES, 2010), Oscilação Decadal do pacífico além dos fenômenos internos a Terra (BARROS; SOUSA; SOUZA, 2014).

Não se pode esquecer que as mudanças climáticas envolvem escalas geológicas longas, muito superiores ao tempo de vida do ser humano. Análises sobre uma perspectiva de tempo tão longo não compactua com a ideia de equilíbrio (SILVA; FERNANDES, 2010). Além disso, as primeiras medições da temperatura média anual começaram apenas no século XIX, o que é irrisório perto do tempo de existência da Terra (VELTRONE, 2015).

Desse modo, o que se tem nesse momento da história é que após muitas décadas de corroboração da teoria da exacerbação do efeito estufa por gases antropogênicos começam a surgir cientistas que tentam refutar essa hipótese, porém, se vão ou não conseguir, só o tempo irá dizer. O importante é enfatizar que o efeito estufa não deve ser tratado como uma Lei, mas como uma teoria passível de refutação. É também importante deixar claro que embora se faça um alarde sobre os relatórios climáticos publicados pelo IPCC (Intergovernmental Panel on Climate Change) confirmando o aquecimento global antrópico, quase em clima de "comprovação", geólogos como Fred Singer, Dennis Avery e Patrick Michaels afirmam que o IPCC é composto por uma maioria que representa o interesse da indústria de mitigação de carbono ao invés de cientistas, o que compromete sua lisura (VELTRONE, 2015). Dessa forma criaram o NIPCC (Nongovernmental International Panel on Climate Change), liderado por Singer, para contestar as posições do IPCC. Embora esse grupo não esteja atrelado ao governo, também não há como garantir sua probidade devido o apego a corrente ideológica.

Essa disputa ideológica nutrida por interesses prejudica o cidadão e atrasa a ciência, o que torna ainda mais crucial o papel da escola na formação do pensamento crítico, pois somente a participação popular possibilita um caminho de regulamentação na busca pelo bem coletivo.

A inversão de causa e efeito tem estado constantemente presente em reportagens e discursos estereotipados. Autores já verificaram a postura dogmática e catastrófica do fenômeno nas revistas brasileiras de maior circulação no país como a Veja, Istoé e Época. Estas revistas fazem uso do tom alarmista, além do seu conteúdo pouco científico e, muitas vezes, equivocado (HEINZ et al., 2008). A vertente catastrófica inicia-se nas capas das revistas, através de manchetes e imagens impactantes, se consolidando no interior da notícia com o anúncio de um iminente fim do mundo (XAVIER, 2004). Esse viés sensacionalista provavelmente se correlaciona com o intuito de venda. Assim, embora criticável, desde que haja limite, tal estratégia é compreensível, porém a passividade do leitor frente ao caráter exagerado das manchetes não deve existir na sala de aula.

Silva, Araújo e Santos (2016) relatam que ao inserir na sala de aula um debate referente ao aquecimento global apresentando aos alunos a concepção antropocêntrica e natural, as quais eles denominaram hegemônica e contrahegemônica, respectivamente, aproximadamente $80 \%$ dos alunos tinham como única concepção a do conhecimento hegemônico. Dessa forma, a discussão despertou nos discentes uma inquietação frente à omissão da tese contrahegemônica pelos livros didáticos, professores e a mídia em geral. Além disso, foi constatado que o debate estimulou o pensamento e a expressão crítica ancorada 
em um discurso sociopolítico o que favoreceu a desmistificação de visões deformadas da ciência como, por exemplo, a neutralidade.

Pesquisas, que investigam as concepções frente às controvérsias do aquecimento global como as realizadas por Santos, Azevedo e Cruz (2015) e Silva, Araujo e Santos (2016) com alunos do ensino médio, Schizzi e Noemi (2016) com estudantes universitários do curso de Pedagogia apontam que de forma geral o conhecimento apresentado pelos alunos além de falho tem uma predominância pela versão antropogênica.

Portanto, essas discussões no ensino de ciência são cruciais não apenas para a aprendizagem significativa do conteúdo em questão, mas para o desenvolvimento do pensamento crítico e a desmistificação das visões deformadas da ciência, pontos imprescindíveis em uma formação que visa à cidadania.

Esse compromisso da escola com a formação do pensamento crítico está inclusive preconizado na forma de lei, através da LDB (Lei de Diretrizes e Bases da Educação):

Art.35. O ensino médio, etapa final da educação básica, com duração mínima de três anos, terá como finalidades: Parágrafo III: o aprimoramento do educando como pessoa humana, incluindo a formação ética e o desenvolvimento da autonomia intelectual e do pensamento crítico (BRASIL, 1996).

E também está presente nos PCN (Parâmetros Curriculares Nacionais):

Não se pode simplesmente aceitar a ciência como pronta e acabada e os conceitos atualmente aceitos pelos cientistas e ensinados nas escolas como "verdade absoluta" (BRASIL, 2000).

Entre os recursos disponíveis para auxiliar o professor a cumprir o que está na LDB e PCN, o livro didático é o de maior acessibilidade para as escolas e às vezes o único contato com livro que muitos alunos têm (SCHNETZLER, 1981). E hoje, graças ao Plano Nacional do Livro Didático (PNLD), um maior número de alunos tem acesso a livros de qualidade.

O Programa Nacional do Livro Didático (PNLD) tem como principal objetivo subsidiar o trabalho pedagógico dos professores por meio da distribuição de coleções de livros didáticos aos alunos da educação básica. O programa é executado em ciclos trienais alternados. Assim, a cada ano o MEC adquire e distribui livros para todos os alunos de um segmento, que pode ser: anos iniciais do ensino fundamental, anos finais do ensino fundamental ou ensino médio. À exceção dos livros consumíveis, os livros distribuídos deverão ser conservados e devolvidos para utilização por outros alunos por um período de três anos.

O PNLD também atende aos alunos que são público-alvo da educação especial. São distribuídas obras didáticas em Braille de língua portuguesa, matemática, ciências, história, geografia e dicionários. (PNLD, 2016).

Para fazerem parte no PNLD, as obras precisam ser inscritas em edital específico pelos detentores dos direitos autorais e, portanto devem atender aos critérios estabelecidos previamente. Caso sejam aprovadas, irão compor o Guia do Livro Didático que é enviado para todas as escolas públicas e que servirá de 
orientação para o corpo docente e diretivo na escolha de qual obra adotarão para os próximos três anos letivos.

No Guia do Livro didático são apresentadas as resenhas das obras aprovadas e os parâmetros que nortearam a avaliação. Os critérios vão sendo modificados em cada edital com o intuito de incorporar inovações. Por exemplo, o edital para o PNLD 2018 (Edital 04/2015) com data de cadastramento de editores e suas obras didáticas até o dia 30/05/2016 estabeleceu, entre outros, que as obras de Língua Portuguesa, Matemática, História, Geografia, Física, Química, Biologia, Língua Estrangeira Moderna (Inglês), Língua Estrangeira Moderna (Espanhol), Sociologia, Filosofia e Artes destinadas aos estudantes e professores do ensino médio, deveriam:

-3.1.6. (...) incluir referências a interfaces pedagógicas entre as áreas afins e também a outras áreas de conhecimento, bem como conduzir os estudantes a atividades de experimentação e situações reais para consolidação da aprendizagem (PNLD, 2016).

Dessa forma, o PNLD é um importante instrumento da democratização do conhecimento, pois possibilita que alunos de pequenas cidades nas regiões mais remotas do Brasil tenham acesso ao mesmo conjunto de informação que os das grandes metrópoles brasileiras.

Assim, tendo em vista a importância do livro didático e a necessidade de que se rompa com o estereótipo de uma ciência dogmática, somada a crucialidade de temas ambientais na sala de aula, este trabalho objetiva avaliar como o efeito estufa é discutido nos livros didáticos de Química aprovados pelo PNLD 2008 e 2012 à luz da filosofia da ciência, questionando se os mesmos fortalecem uma visão estereotipada do fenômeno efeito estufa.

\section{METODOLOGIA}

Foi realizada uma leitura diagonal dos livros de Química aprovados pelo Programa Nacional do Livro Didático 2008 (PNLD/2008) e 2012 (PNLD/2012) selecionando os textos que se referiam ao tema Efeito Estufa (Tabela 1). Em posse destes foi feita uma releitura fazendo admoestações sob a luz da filosofia da ciência visando responder a seguinte questão de pesquisa: 0 discurso presente nos livros analisados apresenta uma visão estereotipada do Efeito Estufa?

Tabela 1. Livros utilizados na análise sobre a abordagem do tema efeito estufa.

\section{PNLEM 2008}

NÓBREGA, O. S.; SILVA, E. R.; SILVA, R. H. Química. São Paulo: Ática, 2005.

SANTOS, W. L. P. dos; CASTRO, E. N. F. de; SILVA, G. de S.; MÓL, G. de S.; MATSUNUGA, R. T.; FARIAS, S. B. F.; SANTOS, S. M. de O.; DIB, S. M. F. Química e Sociedade. São Paulo: Nova Geração, 2005.

FELTRE, R. Química. São Paulo: Moderna, 2005.

CANTO, E. L.; PERUZZO, F. M. Química na abordagem do cotidiano. São Paulo: Moderna, 2005.

BIANCHI, J. C. de A; ABRECHT, C. H.; MAIA, D. J. Universo da Química. São Paulo: FTD, 2005. 
SANTOS, W.L.P. dos; CASTRO, E. N. F. de; SILVA, G. de S.; MÓL, G. de S.;

MATSUNUGA, R.T.; FARIAS, S.B.F.; SANTOS, S.M. de O.; DIB, S. M. F.

Química Cidadã. São Paulo: Nova Geração, 2010.

REIS, M. Química-Meio Ambiente-Cidadania-Tecnologia. São Paulo: FTD,

2010.

LISBOA, J. C. F. Ser protagonista química. São Paulo: SM, 2010.

CANTO, E. L. do; PERUZZO, F. M. Química na abordagem do cotidiano.

São Paulo:Moderna, 2010.

MORTIMER, E. F.; MACHADO, A. H. Química. São Paulo: Scipione, 2011.

Para responder a questão de pesquisa foi definido, em dois critérios, o que seria considerado uma visão estereotipada, como pode ser observado na Tabela 2.

Tabela 2. Critérios para determinar se o Efeito Estufa é divulgado de forma estereotipada.

\begin{tabular}{l|l}
$\begin{array}{l}\text { Visão Estereotipada do Efeito } \\
\text { Estufa }\end{array}$ & \multicolumn{1}{c}{$\begin{array}{c}\text { Visão não estereotipada do } \\
\text { Efeito Estufa }\end{array}$} \\
\hline $\begin{array}{l}\text { É temperatura média atual: } \\
\text { devido a maior concentração de } \\
\text { gases estufa. }\end{array}$ & $\begin{array}{l}\text { Não é passível de considerações, } \\
\text { pois não existem dados } \\
\text { suficientes para garantir que já } \\
\text { tenha existido um período de } \\
\text { estabilidade. Além do início das } \\
\text { medições ser recente, há que se } \\
\text { considerar a variação da } \\
\text { tecnologia empregada nessas } \\
\text { mensurações e a posição } \\
\text { geográfica das estações } \\
\text { climatológicas que, hoje, podem } \\
\text { estar sitiadas em ilhas de calor. } \\
\text { Uma possível mudança na } \\
\text { temperatura média é resultado } \\
\text { da variação na taxa de escape da } \\
\text { energia térmica da atmosfera que } \\
\text { pode ou não ser resultado de } \\
\text { uma variação na concentração de } \\
\text { gases estufas, mas também pode } \\
\text { ser resultado da variação na } \\
\text { incidência de radiação na } \\
\text { atmosfera, além de outros } \\
\text { fatores. }\end{array}$ \\
\hline
\end{tabular}

As consequências de um aumento na concentração dos gases estufas são:

-Destruidoras
-Catastróficas
-Destruição de alguns sistemas;

-Estimulação de outros sistemas; -Neutralidade para outros sistemas; 


\section{RESULTADOS}

\section{Critério 1: A temperatura média atual}

A partir das considerações explicitadas na Metodologia para definir o primeiro critério, ao analisar os livros aprovados pelo MEC percebe-se que, de forma geral, vem ocorrendo uma disseminação da versão estereotipada do efeito estufa. O viés da teoria como verdade absoluta pode ser constatado em vários momentos nos livros de Química analisados. Os autores além de não colocarem em dúvida se existem de fato variações na temperatura média da Terra defendem, de forma unânime, que a Terra está vivenciando um período de aquecimento global ocasionado pelo aumento dos gases estufa conforme os exemplos:

Como consequência, o efeito estufa vem se intensificando, pois maiores quantidades de $\mathrm{CO}_{2}$ na atmosfera, retém cada vez mais radiações infravermelhas refletidas pela Terra, impedindo essas radiações de "escapar" para o espaço exterior (FELTRE, 2005, p.333);

Com mais dióxido de carbono, a atmosfera absorve uma quantidade maior de radiação infravermelha emitida pela superfície terrestre, aquecendo mais do que deveria. O resultado é o aumento da temperatura em todo o planeta, o chamado aquecimento global (SANTOS et.al, 2005, p.121);

$\mathrm{O}$ aumento da concentração de $\mathrm{CO}_{2}$ na atmosfera, resultante da queima em grande escala de combustíveis fósseis, esta associado claramente ao aumento do efeito estufa, que pode resultar no aquecimento global do planeta (MORTIMER; MACHADO, 2011, v.2, p. 50);

O problema é que as atividades humanas, como a queima de combustíveis fósseis (...) têm liberado uma enorme quantidade de gases de efeito estufa para a atmosfera (...) Com o efeito estufa potencializado, a temperatura média do planeta tende a aumentar (REIS, 2010, v.1, p.34).

(...) com mais dióxido de carbono, a atmosfera absorve maior quantidade de radiação infravermelha emitida pela superfície terrestre, aquecendo mais do que deveria. O resultado é o aumento da temperatura em todo o planeta, o chamado aquecimento global (SANTOS et al, 2010, v.1, p. 128).

Essas foram apenas algumas das várias passagens estereotipadas da teoria presente nas coleções. Para evita-las, é preciso que os autores discutam o tempo de existência da Terra, o início das medições da temperatura média, as diferentes tecnologias empregadas para as mensurações em diferentes períodos históricos, - número de estações climatológicas e onde se localizam. Todas essas informações são indispensáveis quando se visa definir equilíbrio, pois não é possível afirmar que está havendo uma mudança no equilíbrio da temperatura sem antes dialogar sobre o que é esse equilíbrio, se ele de fato já existiu, por quanto tempo e sob quais condições? É necessário que se construam discussões sobre o números de dados existentes, se seriam eles suficientes para se fazer alguma consideração sobre a atual temperatura média e, ainda, se os mesmos permitem a realização de projeções sobre futuros cenários.

Além do equilíbrio da temperatura média da Terra, é preciso também 
fenômenos internos a Terra entre outros, pois todos esse fatores influenciam na temperatura média e portanto, não podem ser desconsiderados.

Afirmar categoricamente que estamos vivenciando um aquecimento global ocasionado pelos gases estufas sob responsabilidade humana sem elencar e considerar outras variáveis é desconsiderar toda a complexidade do sistema atmosférico, é assumir uma postura estereotipada que vai contra o princípio básico da ciência, o que discute a impossibilidade de se estar frente a frente com a verdade absoluta para representá-la em modelos e teorias.

Critério 2: As consequências de um aumento na concentração dos gases estufas

Para os livros analisados a incerteza acerca da teoria do efeito estufa não reside na própria teoria, nem nos métodos empregados cientificamente por pesquisadores sobre o tema, tão pouco na responsabilidade humana. A insegurança recai apenas na dimensão das catástrofes que sua intensificação poderá provocar. Segundo os autores, o resultado será necessariamente caótico:

(...) o tema efeito estufa é bastante polêmico. As controvérsias não se relacionam, contudo, com a existência do efeito em si, que está muito bem comprovada, mas sim às previsões sobre o que poderá acontecer nas próximas décadas (CANTO; PERUZZO, 2005, p.234; CANTO; PERUZZO, 2010, v.2, p.316).

O problema é o desequilíbrio nas quantidades desses gases (aumento), elevando a temperatura média da Terra com consequências imprevisíveis ao planeta (BIANCHI; ABRECHT; MAIA, 2005, p.452).

(...) por meio da queima de combustíveis fósseis, têm sido expelidas para a atmosfera na forma de gás carbônico, o que aumenta as consequências funestas do efeito estufa (LISBOA, 2010, v.3, p.17)

Portanto, de forma geral, os autores apresentam apenas as consequências caóticas como o derretimento de parte das calotas polares (FELTRE, 2005; NÓBREGA; SILVA; SILVA, 2005; SANTOS et al., 2005; 2010; REIS, 2010; CANTO; PERUZZO, 2010;) resultando em um aumento do nível médio dos oceanos e inundações (FELTRE, 2005; CANTO; PERUZZO, 2005; 2010; NÓBREGA; SILVA; SILVA, 2005; SANTOS et al., 2005; REIS, 2010), o que acarretará no desaparecimento de grandes extensões de terra e de muitas cidades litorâneas (NÓBREGA; SILVA; SILVA, 2005; SANTOS et al., 2005; 2010; CANTO; PERUZZO, 2010); redução das chuvas (FELTRE, 2005; SANTOS et al., 2005; CANTO; PERUZZO, 2010), colocando em risco a agricultura (CANTO; PERUZZO, 2005; 2010) e transformando vastas regiões em desertos (NÓBREGA; SILVA; SILVA, 2005; REIS, 2010, SANTOS et al., 2010). Chuvas torrenciais, inundações (FELTRE, 2005; SANTOS et al., 2005; 2010; CANTO; PERUZZO, 2010; NÓBREGA; SILVA; SILVA, 2005; REIS, 2010;), tempestades e furacões (CANTO; PERUZZO, 2005; 2010; FELTRE, 2005; REIS, 2010; SANTOS et al., 2010); doenças tropicais avançando fronteiras (SANTOS et al., 2005; LISBOA, 2010) e aumento do número de espécies em extinção (SANTOS et al., 2010).

Não obstante, além das possíveis consequências negativas anunciadas, na tentativa de inflar e provar o impacto catastrófico das emissões de gases estufa os autores correlacionam as emissões de gases com calamidades já noticiadas de 
forma a indicar que a vingança da natureza não apenas começou como é inevitável. Além disso, os autores predominantemente culpam o homem por essa exacerbação omitindo a possibilidade de um efeito natural, como já experimentado pelo planeta diversas vezes.

(...) O aquecimento global seria a causa de 160.000 mortes por ano, no mundo; O governo francês admitiu 10.000 mortos devido aos efeitos do calor no verão de 2003 (FELTRE, 2005, p.334).

Imagens impactantes relacionadas às diferentes possibilidades de catástrofe são frequentemente utilizadas como recurso auxiliar na defesa do princípio de que há uma bem estabelecida relação entre causas e efeitos. Estas mesmas imagens têm também a finalidade de reforçar as previsões negativas envolvendo o tema efeito estufa, previsões estas que são enfaticamente desenvolvidas na forma de argumentos que desconsideram a complexidade do sistema Terra e das relações entre as atividades humanas e o ambiente. Na Figura 2 são apresentados alguns exemplos deste tipo de recurso, bastante comum nos livros didáticos.

Figura 2- Imagens correlacionadas ao Efeito Estufa pelo livro didático

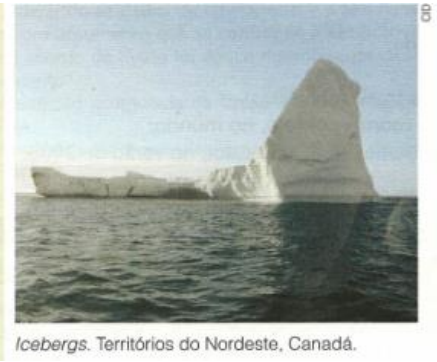

(fonte: FELTRE, 2005, p.333)

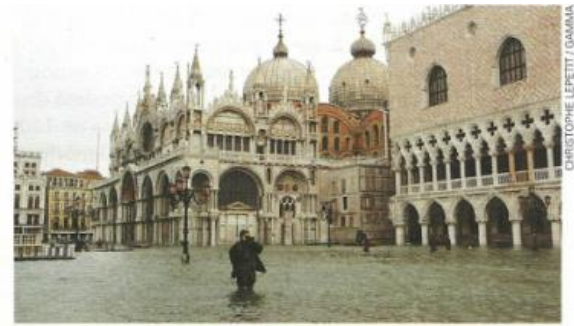

Praça de Săo Marcos inundada. Veneza, Itália, 17/11/2002.

Dentre os autores dos livros didáticos pesquisados, quem mais se destacou na utilização de recursos de textos e imagens catastróficas foi Reis (2010). A autora inicia um capítulo sobre as mudanças climáticas com várias manchetes chamando a atenção para desastres atuais. Em seu livro é dada ênfase para o fato de que se nenhuma atitude for tomada a tempo, os números desses desastres aumentarão, assim como a intensidade das catástrofes anunciadas, como pode ser visto na Figura 3. 
Figura 3- Manchete inicial no capítulo Mudanças climáticas

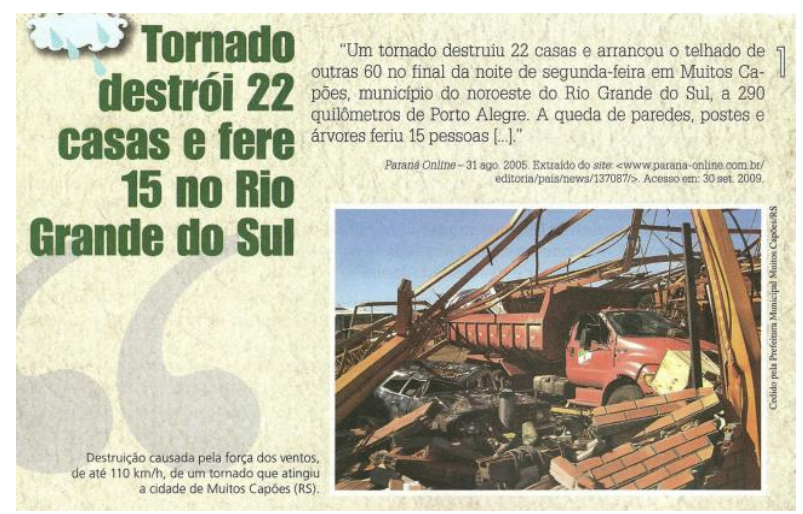

(Fonte: REIS, 2010, p.16)

Em alguns casos os autores também fazem uso de imagens e textos que mostram animais indefesos sofrendo devido a essas mudanças climáticas, provavelmente, com o intuito de mexer com as emoções dos leitores (Figura 4).

Figura 4- Imagem correlacionando o aquecimento global com a morte de animais indefesos.

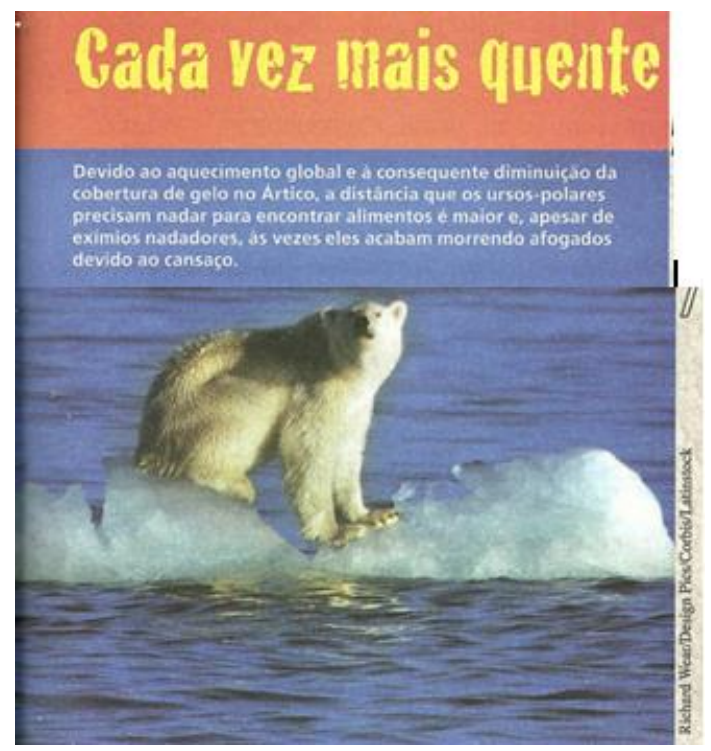

(Fonte: REIS,2010, p.19)

Não é intuito deste trabalho negar o derretimento das geleiras ou o sofrimento dos animais, mas chamar a atenção para a associação absoluta entre causa e efeito que essa abordagem traz consigo usurpando a oportunidade de desenvolvimento do pensamento crítico. O derretimento das geleiras pode ser um fato observado e mensurado, mas a associação desse fenômeno com o efeito estufa não é mais do que uma hipótese. Assim, ao invés de relatarem essa ligação como incontestável como foi feito pela maioria dos autores, é mais salutar a abordagem elegida por Mortimer e Machado (2011) que utilizam as imagens do 
derretimento como uma evidência do aquecimento global e não necessariamente como uma prova da existência do Efeito Estufa ou menos ainda como comprovação da intensificação ocasionada pelo homem (Figura 5).

Figura 5- Derretimento de partes da Antártida como forma de evidenciar o aquecimento global

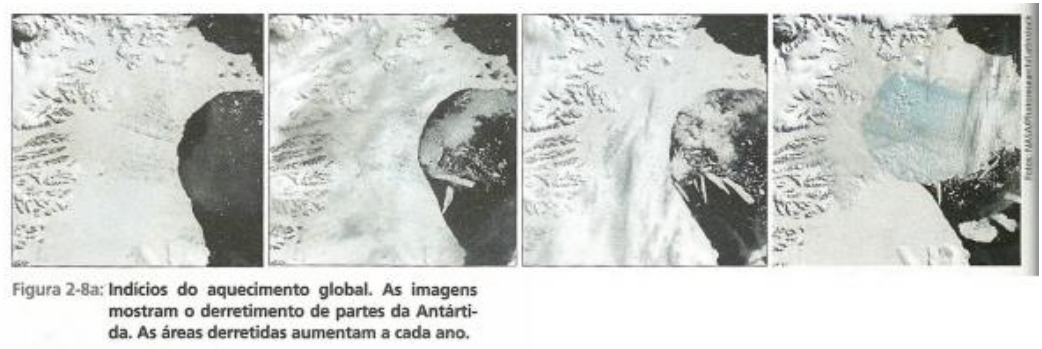

(Fonte: MORTIMER; MACHADO, 2011, p.50)

Ademais, quando os autores optam por divulgar somente as possíveis consequências funestas desconsiderando o impacto positivo, eles reforçam a visão estereotipada do efeito estufa além de contribuir para a política do medo e aterrorizar a população ao invés de formá-la para cidadania. É preciso discutir que há a possibilidades de eventos catastróficos, da destruição de regiões, da extinção de espécies, mas ao mesmo tempo outras regiões se tornaram passíveis de ocupação, novas espécies podem surgir. O planeta Terra existe há alguns bilhões de anos e se transforma continuamente, no seu ritmo, sobrevivendo inclusive a queda de meteoros que dizimaram os dinossauros, as bombas atômicas que destruíram Hiroshima e Nagasaki, e certamente, sobreviverá à variações climáticas .

A política do medo associada às alterações climáticas tem gerado sintomas de depressão, ansiedade e estresse na população. Um exemplo, extremo, de pânico em relação às mudanças climáticas foi noticiado em 02/03/2010. Neste episódio, ocorrido na Argentina, pais mataram um filho de dois anos e a filha de 7 meses e depois cometeram suicídio. Na casa foi encontrada uma carta em que expressavam o desespero ante a falta de ações dos países contra a crise ambiental (OLIVEIRA; VECCHIA; CARNEIRO 2015).

Embora o caso seja extremo, ele não pode ser desconsiderado, mas deve servir de alerta para divulgadores científicos.

Em um ranking sobre a opinião pública em 40 países, os EUA estão entre os que possuem a menor preocupação sobre mudança climática (34a posição). Enquanto o Brasil é o terceiro mais preocupado (OLIVEIRA; VECCHIA; CARNEIRO 2015), esse dado evidencia como é relevante, principalmente no Brasil, a forma como o discurso sobre o aquecimento global é apresentado e o papel da escola que deve formar indivíduos conscientes sem que para isso seja necessário aterrorizá-los.

Desse modo, discorrer sobre os mais ambivalentes resultados é crucial, pois alterações em um sistema complexo tendem a gerar resultados diversos e formação do pensamento crítico preconizado pela LDB e PCN. 
Assim, embora os autores dos livros didáticos façam parecer que o Efeito Estufa é o responsável pela temperatura média na Terra e a exacerbação do mesmo por uma origem antrópica correspondam a verdades absolutas, tais afirmações não o são. Primeiro porque a ideia de verdade absoluta não se sustenta na ciência e, segundo porque não há um consenso entre os cientistas sobre o fato de que as ações humanas são a causa do problema, nem que os gases estufas dificultam o escape da energia térmica de forma significativa. Embora pesquisas indiquem que a maioria da comunidade cientifica relevante aponte para este caminho, há também os defensores de que o homem nada tem a ver com qualquer alteração climática (TOL, 2014; ORESKES, 2004) e estes não podem ser ignorados.

Portanto, é importante que os autores de livros didáticos tenham a clareza de que não é função deles apoiarem uma teoria ou outra, nem esgotarem seus argumentos, apenas fornecerem uma ideia geral sobre a existência e pertinência das mais diversas posições. Não é condenável indicar uma teoria como melhor do que a outra, desde que se explicitem ambas as possibilidades enfatizando que a melhor teoria não significa verdade, pois em ciência existem apenas hipóteses, às vezes mais bem fundamentadas que outras.

Enfim, não é intenção aqui chamar a atenção para a existência ou não do efeito estufa nem afirmar se o aquecimento global está acontecendo e se isto é responsabilidade das ações humanas. O intuito é destacar a importância para o fato de que os autores de livros didáticos devem estar atentos para a necessidade de ressaltar os diversos aspectos de um mesmo fenômeno para que o aluno desenvolva seu pensamento crítico e entenda como a ciência funciona, como são elaboradas hipóteses, teorias, como estas são falseadas e para a importância da discussão (crise-revolução). O efeito estufa aqui é o meio e não o fim e pode ser trabalhado para além de uma abordagem química, pode ter um enfoque filosófico.

\section{CONCLUSÃO}

Os livros de Química analisados neste trabalho discorrem sobre a teoria do Efeito Estufa como se esta fosse um fato determinado e aceito por toda comunidade científica, passando uma visão de que por meio de argumentos supostamente científicos é possível defender ainda uma ciência capaz de expressar uma verdade absoluta. Além disso, os autores de livros didáticos profetizam um quadro que nos remete a possibilidade de "fim do mundo iminente" devido ao aumento da temperatura média global. Para sustentar seus argumentos, são enfaticamente construídas relações entre emissões de gases e aumento da temperatura global com os desastres atuais. Entretanto, todos esses reveses vivenciados, enchentes, furacões, etc. podem não passar de fatalidades acontecendo em um planeta que nunca esteve em equilíbrio, fato este defendido por parte considerável da comunidade científica e negligenciado nos textos e imagens utilizados nos livros didáticos. Abordando o tema efeito estufa dessa forma, os autores contribuem para o desenvolvimento de uma concepção pautada na falsa sensação de homeostase, pois desconsideram o que tem sido observado diante de eventos naturais ocorridos ao longo da longevidade do universo. 


\title{
Stereotypical conceptions about global warming teaching in chemistry books
}

\begin{abstract}
The current period is marked by wide access to information but with questionable content related to the superficiality and emotional exaggeration that characterize them. This paper aims to evaluate how greenhouse effect is discussed in textbook of Chemistry approved in PNLEM 2008 and PNLD 2012 asking if reinforce a stereotypical view of the phenomenon. The results suggest that the catastrophic tone is present both in textual form as collaborating imagery to be tenuous the line between deliberate stereotypical news and that arising from ignorance. This approach made by textbooks walks against the LDB and the PCNs as to omit the controversial character presenting a single view usurps the student the opportunity to develop their critical thinking, which could be favored by the basic principles of scientific philosophy substantiating meaning of science to emphasize the impossibility of reaching an absolute truth.
\end{abstract}

KEYWORDS: greenhouse, textbook, critical thinking. 


\section{REFERÊNCIAS}

ALVES, R. Filosofia da ciência: introdução ao jogo e suas regras. São Paulo: Brasiliense, 1981.

ARRHENIUS, S. On the influence of carbonic acid in the air upon the temperature of the ground. Phislosophical maganize and jornal of Science, v.41, n.251, p. 237-276, 1896.

BARROS, H. S.; SOUSA, L. V. DE; SOUZA, L. D. Aquecimento global: mitos sobre o aceleramento antropogênico. Química: ciência, tecnologia e sociedade, v.3, n.1, p.56-66, 2014.

BLUCHEL, K. G. A fraude do efeito-estufa aquecimento global, mudança climática: os fatos. São Paulo: Publishing House Lobmaier,2008.

BRASIL. Lei de Diretrizes e Bases da Educação 9.394. Brasília, DF, 20 dez, 1996.

BRASIL. Parâmetros Curriculares Nacionais para o Ensino Médio. Ciências da Natureza, Matemática e suas Tecnologias. Brasília, DF, 2000.

CHALMERS, A. F. O que é a ciência afinal? São Paulo: Brasiliense, 1993.

CLIMATE change: synthesis report. IPCC, Geneva, n.5, 2014. Disponível em: <http://www.ipcc.ch/report/ar5/syr/>. Acesso em: 20 out. 2016.

HEINZ, N. P.; FONTANA, P. D.; FERNANDES, M. R. S.; SILVA, M. D. M. DA; Aquecimento Global e Efeito Estufa: análise de coberturas das revistas Veja, IstoÉ e Época no ano de 2006. In: CONGRESSO DE CIÊNCIAS DA COMUNICAÇÃO NA REGIÃO SUL, 9., 2008, Guaraparuva. Anais eletrônicos... Guaraparuva: Intercom, 1996. Disponível em: $<$ http://www.intercom.org.br Lpapers/regionais/sul2008/resumos/R10-0423-1.pdf>. Acesso em: 21 out 2016.

KUHN, T. S. A estrutura das revoluções científicas. São Paulo: Perspectiva, 1998.

MOLION, L. C. B. Desmistificando o aquecimento global. Intergeo, v.5, p. 13-20, 2007.

MOLION, L. C. B. Aquecimento global: uma visão crítica. Revista Brasileira de Climatologia. v.3/4, p. 7-24, 2008. 
MOSCATI, M. C. de L. Desafios associados às mudanças climáticas. Sociedade Brasileira de Meteorologia, v.31, n.1, 2007.

MOZETO, A. A. Química atmosférica: a química sobre nossas cabeças. Cadernos temáticos de Química Nova na Escola. Edição especial. 2001.

OLIVEIRA, M. J. de; VECCHIA, F. A. da S.; CARNEIRO, C. D. R. A educação no contexto do aquecimento global: da ignorância e analfabetismo cientifico ao raciocínio crítico e litrácea climática. Periódico eletrônico Fórum ambiental da alta paulista. v.11, n.4, p.287-310, 2015.

ONÇA, D. de S. A construção da hipótese do aquecimento global: um resgate histórico. Periódico eletrônico Fórum ambiental da alta paulista. v.11, n.4, p.219-231, 2015.

ORESKES, N. The scientific consensus on climate change. Science. v. 306, n.5702, p. 1686-1687, 2004.

PÉREZ, D. G.; MONTORO, I.F.; ALIS, J. C.; CACHAPUZ, A.; PRAIA, J. Para uma imagem não deformada do trabalho científico. Ciência \& Educação, v. 7, n.2. p.125-153, 2001.

PNLD. MEC, Brasilia. 2016. Disponível em: < http://portal.mec.gov.br/pnld/apresentacao>. Acesso em: 13 out. 2016.

POPPER, K.R. A lógica da pesquisa científica. São Paulo: Pensamento Cultrix LTDA,1972.

PRAIA, J. F.; CACHAPUZ, A. F. C.; GIL-PEREZ, D. Problema, teoria e observação em ciência: para uma reorientação epistemológica da educação em ciência. Ciência \& Educação. v.8, n.1, p.127-145, 2002

RUFATTO, C. A.; CARBONE, M. C. A concepção de ciência de Popper e o ensino de ciências. Ciência \& Educação (Bauru), v.15, n.2, p.269-289, 2009.

SANTOS, E. da P.; S. L. D. dos, AZEVEDO, R. M.; CRUZ, M. C. P. Concepções de alunos do ensino médio sobre efeito estufa e aquecimento global numa perspectiva de ensino CTS. Revista vivência em educação química. v.1, n.2, p.8195, 2015. 
equilíbrio ambiental e sustentabilidade. Disciplinarum Scientia. Série: Naturais e Tecnologia, v.16, n.3, p.413-431, 2015.

SCHNETZLER, R. P. Um estudo sobre o tratamento do conhecimento químico em livros didáticos brasileiros dirigidos ao ensino secundário de química de 1875 a 1978. Química Nova. v.4, n.1, p.6-15, 1981.

SILVA, A. J.; ARAÚJO, W. S. de; SANTOS, W. L. P. A controvérsia científica como catalisadora de engajamento sociopolítico. Indagatio Didactica, v.8, n.1, p. 19011916, 2016.

SILVA, R. E. C.; FERNANDES, E. Mudanças Climáticas: um panorama das discussões atuais. Sociedade e Território, v.22, n.1, p.2-16, 2010.

TOL, R. S. J. Quantifying the consensus on anthropogenic global warming in the literature: A re-analysis. Energy Policy. v.73, p.701-705, 2014.

VELTRONE, A. R. As ciências sociais e as controvérsias em torno da mudança climática. Estação científica, v.5, n.1, p. 9-21, 2015.

XAVIER, M. E. R. A análise do efeito estufa em textos paradidáticos e periódicos jornalísticos. Caderno Brasileiro de Ensino de Física, v.21, n.3, p.325-349, 2004. 
Como citar: TOLEDO, E. J. L; FERREIRA, L. H. Concepções estereotipadas sobre o aquecimento global em livros didáticos de química. Revista Brasileira de Ensino de Ciência e Tecnologia, v. 10, n. 2, 2017. Disponível em: <https://revistas.utfpr.edu.br/rbect/article/view/2936>. Acesso em: xxx.

\section{Correspondência:}

${ }^{1}$ Instituto de Química. Universidade de Brasília, Asa Norte, 70910-900 -Brasília -Distrito Federal.

${ }^{2}$ Departamento de Química. Universidade Federal de São Carlos, Rodovia Washington Luís, 13565-905- São Carlos-SP.

Direito autoral: Este artigo está licenciado sob os termos da Licença Creative Commons-Atribuição 4.0 Internacional. 